\title{
Observations on
}

\section{A Matching Program to Retrain Inactive Medical Technologists}

NORMAN E. HOLLY

A PPROXIMATELY 56,000 medical technologists are certified or eligible for certification by the Board of Registry of Medical Technologists of the American Society of Clinical Pathologists. Of this number an estimated 40,000 are employed full or part time in the nation's 14,000 medical laboratories. Roughly nine-tenths of the technologists are women.

American Medical Association-approved schools of medical technology graduate another 4,000 technologists annually. But nearly 1,800 of all active technologists leave their profession each year, mostly for marriage and family. Subsequent reemployment of even some of these inactive technologists obviously would alleviate chronic shortages of skilled medical laboratory manpower.

In 1965 the National Committee for Careers

Mr. Holly is a health economist in the Office of International Health, Office of the Secretary, Department of Health, Education, and Welfare. He was formerly special assistant for health economics, $\mathrm{Bu}$ reau of Health Manpower (now Bureau of Health Professions Education and Manpower Training), Public Health Service, and consultant to the $\mathrm{Na}$ tional Committee for Careers in Medical Technology. The matching program described in this paper is phase 1 of the Back-to-Work Project, sponsored by the National Committee for Careers in Medical Technology under Public Health Service contract PH-108-66-151. in Medical Technology (NCCMT) - a joint manpower effort of the American Society of Medical Technologists, the American Society of Clinical Pathologists, and the College of American Pathologists-noted that the annual reregistration of several thousand inactive technologists indicated a potential manpower pool and suggested a reactivation program. The premise was tested by an employment survey among all technologists reregistering in 1965, and during the following year a contract was negotiated between NCCMT and the Public Health Service for a nationwide job-matching program.

Under the matching program, NCCMT identified retraining facilities and employment opportunities and effected contact between these institutions and inactive technologists within commuting distance. Generally, no formal retraining program was offered, although some participating laboratories conducted brief onthe-job refresher training, and a few offered stipends or salary during the retraining period. Followup and analysis of the matching were conducted by NCCMT at the conclusion of the program.

\section{The Employment Survey}

Annually in September the Board of Registry of Medical Technologists mails an application for renewal of certification to all technologists registered with the American Society of 
Clinical Pathologists. With the registry's cooperation, an employment survey questionnaire was enclosed with the September 1965 mailing. It contained five question categories, only one of which pertained to each respondent. About 25,000 respondents returned the questionnaires, from which a sample of 3,369 replies was selected for analysis. The sample distribution is shown in table 1.

$A$ breakdown of categories $\mathrm{C}$ and $\mathrm{D}$ revealed that nearly two-thirds of all inactive technologists interested in resuming their careers had interrupted their employment within the previous 5 years. Of those considering future but not immediate reemployment (category $\mathrm{D}$ ), onefourth anticipated returning within 3 years and nearly half anticipated returning within 5 years. More than four of five respondents wishing immediate reemployment (category $\mathrm{C}$ ) preferred part-time work.

Retraining appeared to be a significant factor in reemployment. Of those technologists who had interrupted their careers but later resumed employment (category B), 7 percent undertook retraining in schools of medical technology, 19 percent would have done so had programs been available, and 73 percent retrained on the job. Similarly, most inactive technologists wishing immediate reemployment (category C) expressed a desire for retraining in schools of medical technology (28 percent) or on-the-job training (61 percent).

Projections of the sample analysis to the total registration of active and inactive technologists (about 46,000 at that time) suggested an immediately available manpower pool approaching 1,800-equivalent to half the annual output of U.S. schools of medical technology-and a future reserve of about 6,700 .

\section{The Matching Program}

To validate data on available technologists as indicated by the survey, a second questionnaire was mailed in July 1966. It brought 778 affirmative replies for placement within the near future. Concurrently, a list was compiled of 1,315 American Medical Association-approved schools of medical technology and clinical laboratories willing to participate in the matching program.

The two lists were matched geographically.
Each technologist was then informed of nearby retraining opportunities, and each school and laboratory was informed of all nearby technologists desiring retraining and reemployment. As the program progressed, additional publicity was disseminated to the American Society of Medical Technologists, to State societies, and to professional publications in an effort to increase the number of participating technologists. Results from the matching were surveyed through followup questionnaires to participating technologists and institutions in February 1967.

On the basis of projections from the employment survey profile (table 1), placement of approximately 165 participating technologists might have been expected, assuming satisfactory commuting, working, and domestic situations. Actually, the program achieved only 53 arrangements for retraining and reemployment. Another 49 technologists acquired medical laboratory appointments independent of the matching program, either before receiving their matching lists or in situations not included in the lists. Some, but probably not all, of these 49 may have been inspired to seek employment by the matching program and attendant publicity.

Eighteen participating technologists accepted appointments outside the field of medical technology during the course of the program. Presumably, nearly one-third of all responding

Table 1. Employment survey profile for medical technologists

Respondent category $\begin{gathered}\text { Number } \\ \text { in group }\end{gathered} \begin{gathered}\text { Percent } \\ \text { of sample }\end{gathered}$ A. Worked continuously in a
medical laboratory since certification. ..........
2,176
64. 5
B. Interrupted career for a period of years and then returned to laboratory work.
C. Not employed as a medical
technologist for a period of years but desires to resume laboratory career.-
D. Terminated laboratory em- ployment but might con- sider future reemploy- ment............... . . .
E. Terminated laboratory
career with no intention of returning.............. 154
Total
3,369
99.7 
technologists remained unemployed.

Of the 778 technologists participating in the matching program, 427 did not respond to the followup inquiry.

Of the 1,315 institutions that participated in the matching program, 423 responded to followup; 38 of the 423 completed arrangements to retrain one or more inactive technologists as a direct result of the program.

Since participation in the matching program was based on the number of inactive technologists who had twice affirmed their desire for retraining and reemployment, it is a matter for speculation that fewer than half of the participants reported during the followup period. Subsequent observations are addressed to this point. Nonreporting technologists may have been unsuccessful in their attempts or may have lost interest, in which event the direct placement rate (table 2) would be closer to 7 percent and the indirect rate (table 2) would be closer to 6 percent.

Although statistical correlation could not be established, there seemed to be a tendency toward greater success in areas having the least disparity between salaries of medical technologists and higher salaries in other professions employing large numbers of women; teaching, for example. Within this context, greater success was noted in areas enjoying lower living costs generally, and less success was noted in sparsely settled areas.
Geographically, technologists experienced greater success in relation to their availability in the southwestern Appalachian and Great Lakes regions and in New England. Areas of least success were Southern and Mountain States and the mid-Atlantic region. (These results may lack general applicability because of the small number of persons involved in some areas.)

\section{Factors Affecting Success of Program}

The following considerations were significant in decisions to engage in retraining agreements. For the most part, they were closely related.

Seriousness of purpose. In general, the majority of technologists and institutions felt little urgency in concluding retraining arrangements. Nearly three-fourths (169) of the 231 reporting technologists who remained unemployed either declined retraining because of family or other personal circumstances—often apparent before they agreed to participate-or simply were not interested in reemployment. Although some indicated they might be interested later, others were clearly testing the market. (It seemed probable that some of the market testers were apprehensive of having "forgotten too much" and were tempted but unwilling to actively seek reemployment.)

These replies were disappointing to the laboratories that initiated contact, but they could elicit little or no response from the technologists

Table 2. Placement of participating technologists

Those benefiting directly from the matching program. They made arrangements for retraining or reemployment or both as a direct result of NCCMT contacts:

Those in training or employed at followup (6 in school, 44 on the job) .....

Those who began retraining but dropped out.

Those who may or may not have benefited indirectly. They made their own arrangements either before receiving the NCCMT list or with laboratories not on the list or with whom a previous relationship existed

Those who made no arrangements for retraining or reemployment as medical technologists:

Those who accepted or remained in jobs other than medical technology -.Those who remained unemployed, as far as can be ascertained from their returns. . . .

No response.

Total__

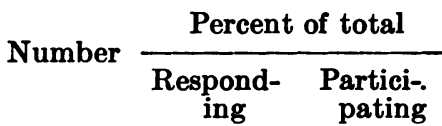


on their lists. Twenty-eight percent of the laboratories that initiated contact found most of the listed technologists uninterested in retraining or reemployment. About half of this number obtained no response from any of the participants referred to them. One hospital in Illinois mailed attractive invitations to 68 technologists referred to them by NCCMT but received only four replies, two of them negative. Ten to 20 fruitless appeals by a single laboratory were not unusual.

Reports like these were received from several laboratories :

I phoned all of the technologists listed within 50 miles. ... Most of them seemed both surprised and annoyed at being called. . . . They all flatly said they were not interested in working. (Pennsylvania)

We ... did not receive a reply from a single one (of 20 contacted). Considering this lack of interest from the technologists, the program in this region appears a failure, and I must cast doubt upon the technologists' motives in registering with your committee. (New Jersey)

We wrote to each medical technologist on the list you sent $u$ s, which contained nineteen names. We had only three replies and these were not interested in a retraining program. (Georgia)

Lack of motivation also was evidenced among many participating laboratories. About twothirds of them failed to initiate contact with the technologists on their lists; rather, they waited for the technologists to reach them. (However, about 40 percent of such instances were excused by laboratory directors as involving unreasonable commuting distances.) Several technologists who initiated contact with referred laboratories also received no reply.

Furthermore, fully 10 percent of all reporting institutions expressed disinterest in retraining technologists, largely because sufficient qualified applicants were available to fill their vacancies. Reports like these were typical:

We fortunately have no openings. ... We even have a waiting list of persons wanting positions. (Tennessee)

Perhaps our fairly comfortable situation ... has accounted for our indolence in pursuing the leads you've furnished. (California)

We did not have a need, nor do we now, for medical technologists. We decided to adopt a wait-and-see attitude as to the eagerness of the people listed to "retrain." (California)

Many technologists who desired only parttime work, generally because of family responsibilities, could find no laboratory willing to accommodate them. Reports like this were received:
I am finding it very dificult in trying to return to parttime work. Several hospitals have said specifically "no part-time" work. After filling out application forms, I just don't hear from the hospital again. (Teras)

An unexpected disappointment developed concerning Veterans' Administration (VA) schools of medical technology; some were apparently encouraged to participate in the matching program without a suitable appropriation. For example, a VA laboratory director in Minnesota reported that "Government has plans to retrain, but hasn't implemented them yet-no staff, no stipends, etc."

Commuting distance. More than one-fourth of the technologists who remained unemployed (62 of 231) cited commuting distance as the major factor. More than one-fourth of the reporting laboratories (113 of 423) also regarded commuting distance as a positive deterrent to retraining the technologists referred to them. As one hospital in Iowa put it, "Most of the students lived too far away and would not be of value to us on completion of training." (NCCMT took commuting distances into consideration in compiling its lists of referral technologists and laboratories but may have underestimated either the distances or the difficulties involved.)

Salary and working conditions. Technologists' reports showed that poor salaries and working conditions constituted major impediments to reemployment. One technologist, for example, reported having been referred to a county hospital laboratory that he had quit a year earlier "as chief MT at a salary of $\$ 280$ per month with no call pay or fringe benefits . . . compelled to work sometimes 60 hours weekly." He preferred not to return because of the laboratory's "chronic turnover problem." (Georgia)

Another participant encountered wide dissatisfaction among full-time technologists in the (Missouri) laboratory to which she reported for retraining. Some participants recommended against further referrals to particular institutions because of poor employee relations or working conditions. Occasionally an institution volunteered that the salaries it could offer had little appeal. In some localities experienced. technologists found alternate employment opportunities, usually at salaries higher than those offered in medical technology. 
It is often assumed that married women will accept low salaries to supplement regular family income or to satisfy psychological needs for professional and social contact. However, it may more generally be true, in the professions as least, that the cost of working exceeds the income or at least does not add enough to make working worthwhile. Relatively few mothers are so comfortably situated that they can tolerate economic loss, no matter how great their dedication. Indeed, the strongest complaints about uneconomic salaries appeared to emanate from the frustration of former laboratory workers still highly dedicated to their profession.

Inflexible hours and an unwillingness by laboratories to accommodate family priorities were other deterrents to reaching agreements. $\mathbf{A}$ Pennsylvania technologist voiced suspicion, also implied by others, that some hospitals and laboratories offered retraining in order to recruit "flunkeys" at "slave wages." She said :

No hospital wants to accept a married woman with children for part-time work. The pay offered is equivalent to that of an unskilled worker. I filled out application after application and met with only frustration. I am changing to secondary education where there is dignity and respect for the college graduate and commensurate salaries. (Pennsylvania)

A group of related complaints concerned the retraining arrangement itself. A number of institutions were unwilling to offer salaries or stipends during the retraining period, and the participants referred to them were unable to underwrite the expenses. Several laboratories geared retraining to their particular needs rather than to the background or career interests of the technologists. A specialist in bacteriology, for example, might be offered retraining only in hematology when a laboratory was short of hematologists.

Not surprisingly, institutions reporting no lack of qualified candidates generally paid above-average salaries, offered full or part salary during retraining, and attempted to accommodate working conditions to family requirements.

Other considerations. Several laboratories complained of the inadequate proficiency and inexperience of some applicants.

Another difficulty, arising from the preponderance of women in the medical technology profession, was the vulnerability of candidates for retraining to the vicissitudes and priorities of family life. Several technologists abandoned the matching program or terminated retraining agreements when their husbands were relocated in employment. Others were precluded from concluding agreements by uncertainties in child care arrangements. Unexpected pregnancies interrupted many plans. Other personal and family problems, of a type that might not have affected the male income producer, were mentioned frequently.

Procedural difficulties. Timing and lapse of time were important factors in the effectiveness of the matching program. Technologists actively interested in reemployment often plan for fall appointments during the previous spring, which accommodates their children's education schedules, coincides with hiring deadlines for school teachers, and leaves their summers unencumbered. Unfortunately, contract negotiations for the matching program extended into June, and consequently the original participant population was cut in half. The long intermission between initial and verification surveys also resulted in losses.

\section{Feedback}

The matching program was funded in accordance with a national effort to reemploy experienced but inactive professional health workers. Provision for retraining was inherent in the program, as an inducement for inactive medical technologists to recover both skill and selfconfidence.

At least 50 to 100 inactive medical technologists resumed their careers through the matching program. They, and the institutions with whom they affiliated, enthusiastically supported the program's objectives and results. Expressions of gratitude were received from several technologists placed through the program whose previous attempts to resume employment had been fruitless. Laboratories and technologists, though unsuccessful in this venture, encouraged the efforts; they also appreciated the seriousness of laboratory personnel shortages and the significance of a national effort to alleviate them.

As a pilot project, the matching program proved valuable in emphasizing some root causes of employee turnover and difficulties im- 
peding the retention and reclaiming of professional skills. This report is devoted exclusively to capitaliring on the usefulness of the suggestions implicit in these observations.

A central factor affecting the success of the matching program was a strong suspicion among both technologists and institutions that the other was not really serious about retraining or reemployment. Many participating laboratory directors felt that inactive technologists preferred not to work or were unwilling to accept the routine and discipline necessary to efficient laboratory operation, that they demanded hours and working situations "on their own terms" and would permit personal and family considerations to interrupt their laboratory performance, and that they expected too much remuneration and offered too little proficiency. Many participating technologists, on the other hand, resented the apparent indifference of laboratory directors to their employment inquiries and regarded the directors as insensitive to family demands or cheap labor and loath to acknowledge the professional standing of medical technologists. The prevalence of such views in both groups was amply indicated in followup reports.

These grievances may have long historical roots and may have been exacerbated by the dramatic shifts of recent years favoring enterprise and large incomes among pathologists. But clearly they contribute only part of the difficulty experienced in rehiring inactive technologists. For even if those technologists who sought only part-time appointments or who were merely testing the market were discounted from the study, an unexpectedly sizable group remains who failed to follow through on earlier expressions of interest for reemployment. It was this group that NCCMT sought to reach during the second phase of its Back-to-Work Project.

In review, the returns suggested that apprehensions among technologists concerning their ability to "catch up" in a rapidly changing profession are deeper than anticipated. During their period of absence, laboratory techniques had changed significantly, owing largely to the impact of automation and the evolution of new instruments. Some aspects of the work seemed totally new ; others, once familiar, now involved different or more complicated procedures. As suggested earlier, this fear of having forgotten too much apparently led to many withdrawals from the matching program and to low response to the followup inquiry.

The initial survey showed that inactive and newly reactivated technologists had desired substantially more didactic retraining than had been available to them. But few of the institutions participating in the matching program offered more than informal on-the-job retraining. The National Committee for Careers in Medical Technology decided to verify and correct this deficiency by taking the following steps.

1. Publishing and distributing "Curriculum Guides for Retraining in Medical Technology," a handbook compiled by laboratory specialists through NCCMT's educational affiliate. This handbook recommends program content and retraining procedures in basic science and several specialties, instrumentation, administration, and supervision, and includes references to audiovisual instructional materials and discussion guides.

2. Initiating an 18-week retraining course through the Georgia Departments of Health, Education, and Labor, co-sponsored by the U.S. Department of Labor. This course comprises 240 hours of lecture and demonstration based on the curriculum guides and 10 weeks of bench observation in six Atlanta hospital laboratory departments. Fifteen retrainees, ranging in age from 32 to 57 years, have been enrolled to date; they had been inactive for periods of 5 to 25 years. Fourteen of the group completed the course; eight of the 14 are now employed full time and the remainder are employed part time.

3. Assisting in the development of a recurring 6-month retraining course, conducted and financed by St. Barnabas Medical Center in Livingston, N.J. This course includes approximately 80 hours of lecture, 540 hours of bench training, and considerable guided reading and programed self-instruction. Eight retrainees, ranging in age from 35 to 50 years, have now completed the course; they had been inactive for periods of 12 to 20 years. All are now employed, mostly part time; four are instructors in the St. Barnabas Medical Center's school for certified laboratory assistants. 
4. Assisting in the development of an 8-week summer course, funded by the National Science Foundation, for 40 inactive technologists specializing in biology and biochemistry. This course was designed by Prof. Elizabeth Austin to satisfy eight units of upper division credit for medical technologists at Sacramento State College. It comprises 64 hours of lecture and 158 hours of clinical laboratory work, with hospital experience made available through the California Association of Medical Technology Schools. (Travel allowances and stipends of $\$ 60$ weekly were also given to participants through the grant.) Twenty technologists have now completed the course; all but one have been reemployed.
Additional insights have been gained through these demonstrations. The break-in periodgenerally the first 3 or 4 weeks-may be traumatic for retrainees and require special assistanco and patience. Existing staff may feel hostile toward the newcomers or resent the additional burden involved in retraining older and, initially at least, fairly unconfident women. Staff directors should be sensitive to these possibilities and seek to obviate them through preliminary staff discussions, "buddy" pairing during retraining, and other measures.

Tearsheet Requests

Norman E. Holly, Office of International Health. Department of Health, Education, and Welfare, Washington, D.C. 20201

\section{Mental Hospital Population Continues to Decline}

For the 14th consecutive year the resident population in State and county mental hospitals in the United States has declined, according to a study by the National Institute of Mental Health, Health Services and Mental Health Administration.

Preliminary data for fiscal year 1969 indicated a resident population-all persons who were physically present for 24 hours per day in the inpatient service or who may have been away on short-term leave, but were expected to return - of 366,815 in State and county mental hospitals. This total represents a drop of 31,034 patients, or about an 8 percent decline over fiscal 1968. In the past 5 years the rate of decline has been accelerating.

Between 1968 and 1969 the rate of decline exceeded 10 percent in 13 States and ranged between 7 and 10 percent in 15 others. In the 5 -year period 1965-69, three States reduced their resident population by half and 20 States by 25 to 50 percent.

The reasons for this decline vary by State and include a multitude of factors even within a single State. Some of the factors, operating to a greater or lesser extent over the entire interval, include increased availability and use of alternate care facilities for the aged, the availability of improved tranquilizing agents, in- creased availability and use of outpatient and aftercare facilities, gradual reduction in length of stays, opening of community mental health centers, affiliation of these centers with State mental hospitals, more effective screening procedures that prevent inappropriate admissions, administrative changes such as the introduction of the geographic unit system, and deliberate administrative efforts to reduce the resident population.

These factors are interrelated and affect the rates of admission, readmission, and duration of stay, which in turn generate changes in the patient population.

According to the study there were 379,838 admissions to State and county mental hospitals in fiscal year 1969. This provisional figure represents an increase of about 3 percent over admissions to these hospitals in 1968. During the past 5 years admissions to these hospitals have increased 20 percent.

Maintenance expenditures for the care of patients in State and county mental hospitals continued to increase in 1969, reaching slightly more than $\$ 1.7$ billion. The daily expenditure per resident patient increased more than 20 percent between 1968 and 1969 and has increased more than 85 percent between 1965 and 1969. 